\title{
Comparison of Solute Clearance, Hospitalization Rate, and Aortic Arch Calcification between Online Hemodiafiltration and High-Flux Hemodialysis: A 6-Year Observational Study
}

\author{
$\mathrm{Na} \mathrm{Hao}^{a}$ Cheng-Hong Yang ${ }^{\mathrm{b}}$ Hong-Tao Yang ${ }^{\mathrm{a}}$ Chien-Hsing $\mathrm{Wu}^{\mathrm{c}}$ \\ Yang-Yang Lei ${ }^{a}$ Yu-Pin Wu ${ }^{c}$ Wan-Ting Lin ${ }^{c}$ Terry Ting-Yu Chiou ${ }^{c}$ \\ Jin-Bor Chen ${ }^{\mathrm{C}}$ \\ aDivision of Nephrology, First Teaching Hospital of Tianjin University of Traditional Chinese \\ Medicine, Tianjin, China; ${ }^{b}$ Department of Electronic Engineering, National Kaohsiung \\ University of Applied Sciences, Kaohsiung, Taiwan; 'Division of Nephrology, Department \\ of Internal Medicine, Kaohsiung Chang Gung Memorial Hospital, Chang Gung University \\ College of Medicine, Chung Shan Medical University School of Medicine, Kaohsiung, Taiwan
}

\section{Keywords}

Hemodiafiltration · High-flux hemodialysis · Aortic arch calcification · Hospitalization · Uremic toxins

\begin{abstract}
Background/Aims: Studies on the long-term clinical benefits of hemodiafiltration (HDF) and high-flux hemodialysis (HFHD) are very limited. This study aimed to investigate the hospitalization rate and aortic arch calcification (AAC) of these two dialysis modalities over 6 years. Methods: Participants who received regular HDF and HFHD in one hospital-facilitated hemodialysis center were prospectively enrolled after matching for age, sex, and diabetes between January 2009 and December 2014. Medical records were reviewed retrospectively on demographics, laboratory variables, calcified scores in aortic arch measured by chest radiography, and rates of hospital admission. Cox proportional hazard regression and linear regression were used to obtain the outcome results. Results: The HDF and HFHD groups consisted of 108 and 102 participants, respectively. Levels of laboratory variables including small soluble solutes and Kt/V were not statistically different over the 6-year period between the HDF and HFHD groups. Calcified scores of the aortic arch increased over 6 years in both groups. The changes in the mean calcified scores were significant when compared between the two groups
\end{abstract}




\section{Kidney \\ Blood Pressure \\ Research}

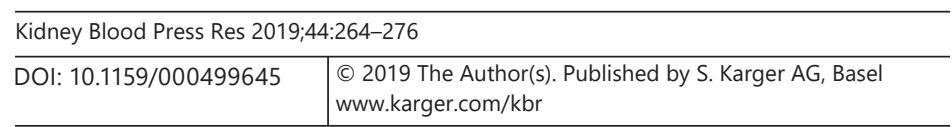

Hao et al.: Hospitalization Rate and Aortic Arch Calcification between HDF and HFHD

(0.44-1.82 in HFHD, 0.79-1.8 in HDF, respectively, $p=0.008$ ). Hospitalization rates were 735 per 1,000 patients in the HDF group and 852 per 1,000 patients in the HFHD group, respectively. No significant difference was observed in frequency and days of hospitalization between HDF and HFHD. Conclusion: Hospitalization rates and AAC were observed to be equal for HDF and HFHD.

(C) 2019 The Author(s)

Published by S. Karger AG, Basel

\section{Introduction}

In the past few decades, hemodialysis (HD) was the main renal replacement therapy in patients with end-stage renal disease (ESRD). Although HD treatment made major scientific and technological progress, the morbidity and mortality of patients with ESRD are higher than those in the general population [1, 2]. Among the etiologies of death, cardiovascular events remain the leading cause of mortality in ESRD [3,4]. Although the causes of high cardiovascular mortality are still uncertain, one of the causes is possibly related to uremic toxicity. Therefore, a dialysis modality can achieve higher elimination in uremic toxins applied in the clinical practice.

Hemodiafiltration (HDF) is a dialysis modality using a kind of high-flux hemodialysis (HFHD) water filter combined with a large number of plasma technology to increase convective transport to remove uremic toxins [5]. Several studies have addressed the advantage of HDF compared with standard HD. The CONvective TRAnsport STudy (CONTRAST) and French Convective versus Hemodialysis in Elderly (FRENCHIE) studies showed the effect of predialysis serum phosphate reduction by HDF therapy [6, 7]. Other studies also demonstrated that HDF therapy is superior compared to standard HD in reducing inflammation [8,9], preventing protein-energy wasting [10], and reducing episodes of intradialytic hypotension [11]. In addition, several studies showed beneficial effects on patient survival. The Dialysis Outcomes and Practice Patterns Study first reported a 35\% lower mortality rate by highervolume HDF compared to low-flux HD [12]. Two European randomized control trials, CONTRAST and Turkish, demonstrated reduced mortality by high convection volumes $(>22$ L/session) in their post hoc analyses $[13,14]$. In the Estudio de Supervivencia de Hemodiafiltración Online study, the primary analysis also demonstrated a 30\% lower risk of both allcause mortality and cardiovascular mortality in patients with HDF than in those with HFHD [15]. However, solid evidence is still lacking to convince all nephrologists believing the widespectrum benefits of HDF therapy when compared to standard HD by head-to-head comparison.

Patients with ESRD are well recognized to have higher risk for cardiovascular mortality [16-18]. Vascular calcification (VC) of the aorta and coronary arteries is considered an important risk factor for cardiovascular disease in patients on dialysis, especially in young adults $[19,20]$. Conventional radiography is a convenient and inexpensive tool for identifying calcium ions in blood vessels [21-23]. In the general population, aortic arch calcification (AAC) found in chest radiotherapy has been shown to be associated with cardiovascular mortality during long-term follow-up [24]. Recent studies have shown that high-grade calcification was associated with cardiovascular and all-cause mortality in patients with HD using plain chest radiography [25].

Owing to a few studies reporting the long-term effect of online HDF, this study aimed to examine the long-term laboratory profile in one cohort of patients with ESRD receiving online HDF therapy over 6 years and compared with those who received HFHD. Moreover, AAC progression on plain chest radiography and rates of hospital admission between HDF and HFHD were examined in this study. 


\section{Kidney \\ Blood Pressure \\ Research}

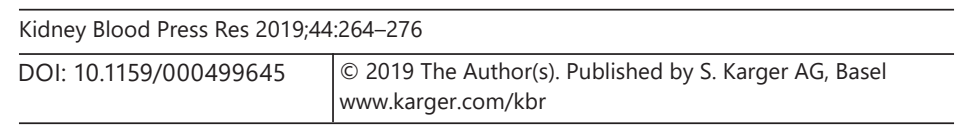

Hao et al.: Hospitalization Rate and Aortic Arch Calcification between HDF and HFHD

\section{Materials and Methods}

\section{Setting}

Patients who received regular HFHD and online post-dilution HDF renal replacement therapy at the outpatient department of Kaohsiung Chang Gung Memorial Hospital in Taiwan were prospectively included between January 1, 2009 and December 31, 2014.

\section{Patients}

Adult patients who received regular online post-dilution HDF and HFHD were prospectively enrolled after matching with age, sex, and diabetes between January 1, 2009 and December 31, 2014. A total of 102 and 108 patients on HDF and HFHD, respectively, were included for medical records review. The choice for online HDF depended on nephrologists' prescription. Vascular accesses included peripheral arteriovenous fistula and arteriovenous graft. The range of blood flow rates was $250-300 \mathrm{~mL} / \mathrm{min}$, and dialysate flow rate was 500 $\mathrm{mL} / \mathrm{min}$. Dialysate sodium (Na) concentration was $140 \mathrm{mEq} / \mathrm{L}$; calcium (Ca) concentration, $3.0 \mathrm{mEq} / \mathrm{L}$; and bicarbonate concentration, $34 \mathrm{mEq} / \mathrm{L}$. The components of dialyzers were ether polysulfone, polysulfone, and polymethyl methacrylate. The surface area of the dialyzer membrane was 2.1-2.5 $\mathrm{m}^{2}$. The convective volume of HDF was 15-25 L.

\section{Data Collection}

Demographic data were collected including age, sex, dialysis vintage, and comorbidity. Data of outcome measures were also collected including rate of hospitalization, frequency and days of hospitalization, and calcification scores of the aortic arch by plain chest radiography between 2009 and 2014. Calcified scores of the aortic arch were measured in 2009 and 2014, respectively.

\section{Laboratory Measurements}

Participants in the study underwent annual hematological and biochemical examinations at the clinic. Baseline values that were collected and measured in December 2009 included hemoglobin ( $\mathrm{Hb}$ ), albumin, blood urea nitrogen (BUN), creatinine ( $\mathrm{Cr}$ ), uric acid, $\mathrm{Na}$, potassium $(\mathrm{K})$, Ca, phosphorus (P), intact parathyroid hormone (iPTH), and Kt/V (Daugirdas method) [26]. All blood samples were analyzed using commercial tools and automated analyzers (Hitachi 7600-210, Hitachi, Tokyo, Japan). Albumin was measured using the bromocresol green method. iPTH level was measured using a chemiluminescence immunoassay (Siemens Healthcare Diagnostics Inc., USA). To measure calcified scores of aortic arch, two independent nephrologists interpreted the X-ray films, Intra-and inter-rater agreement (intraclass correlation coefficient) for AAC score (continuous scale) was 0.93 (95\% confidence interval [CI] $0.91,0.98)$ and $0.90(95 \%$ CI $0.87,0.94)$, respectively. The severity of calcification was classified as grade (Gr.) 0 (no calcification visible), Gr. 1 (single thin or small spots of calcification), Gr. 2 (one or more areas of thick calcification, but $\leq 50 \%$ of the circular area of the aortic knob) and Gr. 3 (circular calcification with $>50 \%$ of circular area of the aortic knob) [27].

\section{Outcome Measures}

The outcome measures included the dynamic changes of serum small soluble solute concentrations and dialysis adequacy index (Kt/V), calcified scores of the aortic arch, rates of hospital admission, and frequency and days of hospitalization in HDF and HFHD between 2009 and 2014. 


\section{Kidney \\ Blood Pressure \\ Research}

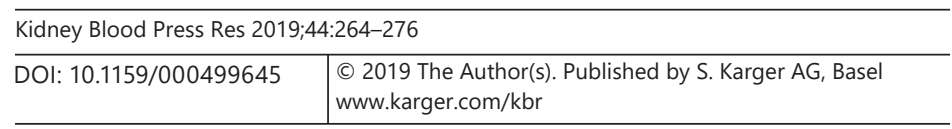

Hao et al.: Hospitalization Rate and Aortic Arch Calcification between HDF and HFHD

\section{Statistical Analysis}

Baseline characteristics and clinical variables of the study population with HDF and HFHD were summarized by frequency (percentage), mean (standard deviation), and median (interquartile range). The difference between the characteristics was estimated using independent two-sample $t$ test, chi-squared test, or Fisher's exact test.

The longitudinal measurements of laboratory data tracked between 2009 and 2014 in HFHD and HDF patients were summarized by mean (standard deviation) or median (interquartile range) and visualized using trend plot by calendar years. The longitudinal changes within and between the HFHD and HDF group is estimated by repeated measures analysis of variance (ANOVA). The associations of longitudinal measurement changes in the HFHD and HDF group were estimated by residual maximum likelihood (REML) linear mixed effects model. We proposed two models in the REML linear mixed effects analysis. The adjusted fixed factors for REML mixed model included age (at baseline), sex, HFHD dialysis vintage, baseline diabetic mellitus status, and comorbidities. Model 1 includes fixed factors only, and Model 2 includes fixed factors and added terms for each measurement and its interaction with time. REML mixed model coefficients and the corresponding 95\% confidence intervals (CI) were reported.

In addition, the different VC status between the HDF and HFHD group in two time-points was estimated using independent two-sample t-test for mean \pm SD and using Fisher's exact or chi-squared test for distribution in categories $0-3$. Paired $t$ test was used to determine the change of VC measured in two time-points for each group, and the repeated measures ANOVA was used to determine the changes of VC in two time-points between the HFHD and HDF group. VC with a score of 3 is considered VC progression.

The hospitalization frequency and total length of stay in the HFHD and HDF groups were summarized using median and range and visualized using a box plot. The association of hospitalization frequency and total length of stay in both groups is estimated using univariate and full-adjusted multivariate linear regression analysis.

A $p$ value of $<0.05$ was considered statistically significant. Stata version 11.0 (StataCorp. 2009. Stata 11 Base Reference Manual. College Station, TX, USA: Stata Press) was used for all statistical analyses.

\section{Results}

A total of 210 participants were analyzed between 2009 and 2014. By age, sex, and diabetes matching, 108 and 102 participants who underwent HFHD and HDF treatment, respectively, were enrolled for comparison. The vintage of HDF treatment was 3.9 years, and there were 7.68 years of HD treatment before HDF in the HDF group. The average length of treatment in the HFHD group was 9.78 years $(p=0.018)$. At baseline, similar serum concentrations of $\mathrm{Hb}$, albumin, and small soluble solutes (BUN, uric acid, $\mathrm{Na}, \mathrm{K}, \mathrm{Ca}, \mathrm{P}$ ) were observed in the HFHD and HDF groups except higher Kt/V levels (1.84 vs. 1.71, $p=0.042$ ) and lower serum Cr concentrations ( $10.98 \mathrm{mg} / \mathrm{dL}$ vs. $11.69 \mathrm{mg} / \mathrm{dL}, p=0.049)$, lower corrected Ca $(9.14$ $\mathrm{mg} / \mathrm{dL}$ vs. $9.40 \mathrm{mg} / \mathrm{dL}, p=0.036)$ in the HDF group than in the HFHD group. Hospitalization cases differ significantly between the HDF and HFHD groups (75 vs. 92, $p=0.036$ ).

Hospitalization rates were 735 per 1,000 and 852 per 1,000 patients in the HDF and HFHD groups, respectively. No significant difference was observed in frequency and days of hospitalization between HDF and HFHD (Table 1).

Table 2 shows the longitudinal data measured annually over the 6-year follow-up in the HFHD and HDF groups. Grossly, the dynamic changes of blood parameters in the individual group were significant in the observational period, except $\mathrm{P}, \mathrm{iPTH}$, and Kt/V levels in the 
Table 1. Baseline characteristics of HFHD and HDF patients $(n=210)$

\begin{tabular}{|c|c|c|c|}
\hline Characteristics & HFHD $(n=108)$ & $\operatorname{HDF}(n=102)$ & $p$ \\
\hline Age, years & $57.56 \pm 8.58$ & $58.74 \pm 11.22$ & 0.395 \\
\hline HFHD dialysis vintage, years & $9.78 \pm 6.52$ & $7.68 \pm 6.11$ & 0.018 \\
\hline HDF dialysis vintage, years & - & $3.9 \pm 2.82$ & - \\
\hline Gender, $n(\%)$ & & & 0.962 \\
\hline Male & $60(55.56 \%)$ & $57(55.88 \%)$ & \\
\hline Female & $48(44.44 \%)$ & $45(44.12 \%)$ & \\
\hline \multicolumn{4}{|l|}{ Comorbidity } \\
\hline $\mathrm{DM}$ & $20(18.52 \%)$ & $28(27.45 \%)$ & 0.123 \\
\hline Hepatitis B & $10(9.26 \%)$ & $6(5.88 \%)$ & 0.357 \\
\hline Hepatitis C & $16(14.81 \%)$ & $19(18.63 \%)$ & 0.459 \\
\hline \multicolumn{4}{|l|}{ Anemia } \\
\hline $\mathrm{Hb}, \mathrm{g} / \mathrm{dL}$ & $10.72 \pm 1.33$ & $10.96 \pm 1.28$ & 0.233 \\
\hline \multicolumn{4}{|l|}{ Nutrition } \\
\hline Albumin, g/dL & $3.96 \pm 0.25$ & $4.02 \pm 0.28$ & 0.119 \\
\hline \multicolumn{4}{|l|}{ Small solute clearance } \\
\hline BUN, mg/dL & $69.5(60-82)$ & $71(58-79)$ & 0.162 \\
\hline $\mathrm{Cr}, \mathrm{mg} / \mathrm{dL}$ & $11.69 \pm 2.28$ & $10.98 \pm 2.29$ & 0.049 \\
\hline Uric acid, mg/dL & $7.04 \pm 1.27$ & $7.16 \pm 1.42$ & 0.589 \\
\hline $\mathrm{Na}, \mathrm{mEq} / \mathrm{L}$ & $136.65 \pm 3.15$ & $135.85 \pm 3.14$ & 0.104 \\
\hline $\mathrm{K}, \mathrm{mEq} / \mathrm{L}$ & $5.12 \pm 0.61$ & $5.08 \pm 0.65$ & 0.656 \\
\hline $\mathrm{Ca}, \mathrm{mg} / \mathrm{dL}$ & $9.37 \pm 0.82$ & $9.16 \pm 0.75$ & 0.090 \\
\hline Corrected Ca, mg/dL & $9.40 \pm 0.81$ & $9.14 \pm 0.76$ & 0.036 \\
\hline $\mathrm{P}, \mathrm{mg} / \mathrm{dL}$ & $5.01 \pm 1.45$ & $5.01 \pm 1.49$ & 0.989 \\
\hline iPTH, pg/mL & $283.15(117.9-537.3)$ & $195.3(56.4-418)$ & 0.062 \\
\hline $\mathrm{Kt} / \mathrm{V}$ & $1.71 \pm 0.46$ & $1.84 \pm 0.4$ & 0.042 \\
\hline Hospitalization cases & $92(85.19 \%)$ & $75(73.53 \%)$ & 0.036 \\
\hline Hospitalization rate (per 1,000 persons) & 852 & 735 & \\
\hline \multicolumn{4}{|l|}{ Hospitalization frequency $(n=167)$} \\
\hline Mean \pm SD & $3.3 \pm 2.68$ & $2.87 \pm 2.22$ & 0.259 \\
\hline Median (range) & $2(1-13)$ & $2(1-11)$ & $0.270^{*}$ \\
\hline \multicolumn{4}{|l|}{ Hospitalization length, days } \\
\hline Mean \pm SD & $37.91 \pm 41.83$ & $38.05 \pm 52.99$ & 0.985 \\
\hline Median (range) & $24(3-201)$ & $19(1-353)$ & $0.198^{*}$ \\
\hline
\end{tabular}

$p$ value is estimated from chi-squared test or independent two-sample $t$ test. ${ }^{*} p$ value is estimated from Kruskal-Wallis test.

HFHD group and BUN, P, iPTH, and Kt/V levels in the HDF group not demonstrating significant dynamic changes. Comparing blood parameters in the study period, significantly higher serum $\mathrm{Cr}$ concentrations were observed in the HFHD group than in the HDF group $(p=0.012)$. Grossly, patients in both groups remained having relative constant serum concentrations of small soluble solutes.

By fixed factors adjustment including age, sex, HD dialysis vintage, and comorbidities, the $\mathrm{HDF}$ group demonstrated significantly higher $\mathrm{Hb}$ (beta $0.41,95 \% \mathrm{CI} 0.12-0.69, p=0.005$ ) and Cr (beta 40.31, 95\% CI 5.89-74.72, $p=0.022$ ) concentrations and lower Ca (beta $-0.92,95 \%$ CI -1.54 to $-0.29, p=0.004$ ), and iPTH (beta $-126.32,95 \%$ CI -230.38 to $-22.26, p=0.017$ ) concentrations compared with the HFHD group. The HDF group showed statistically significant better Kt/V levels in time-varying adjustments compared with the HFHD group after adjusted fixed factors (beta $0.05,95 \%$ CI $0.01-0.1, p=0.025$ ) (Table 3).

Table 4 shows the longitudinal changes of AAC in the participants on HFHD and HDF. The comparison of mean values of calcified scores of the aortic arch between the two groups revealed these values to be significant in the initial phase (2009) (0.44 in HFHD group vs. 0.79 
Kidney

Blood Pressure

Research

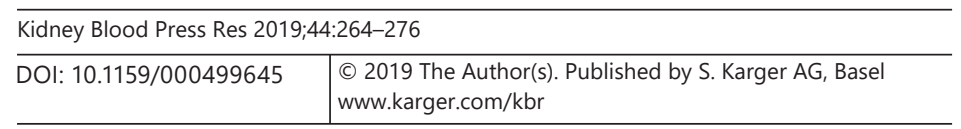

Hao et al.: Hospitalization Rate and Aortic Arch Calcification between HDF and HFHD

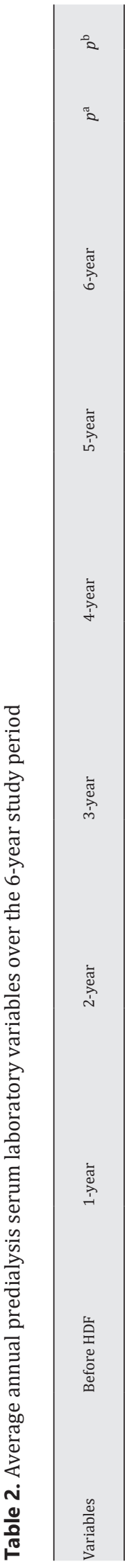

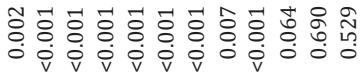

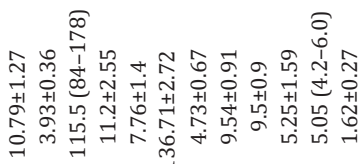

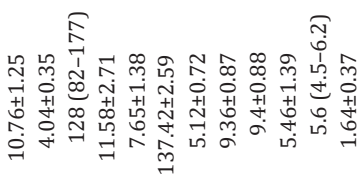
$\stackrel{8}{5}$ 奈

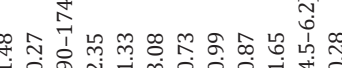
T+1

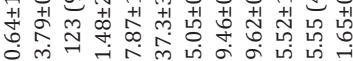

ఫั

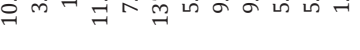

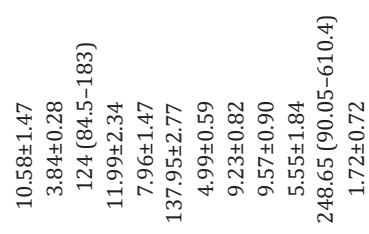

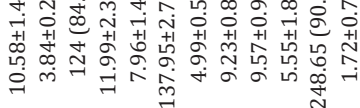

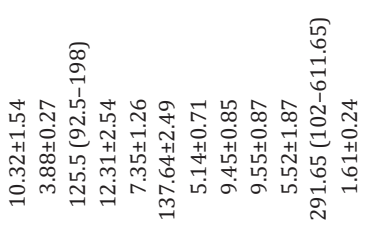

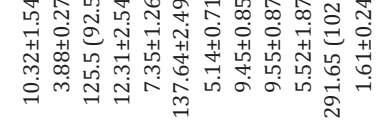
ส

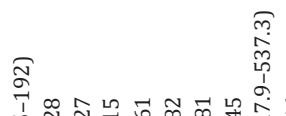

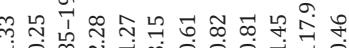

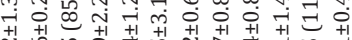

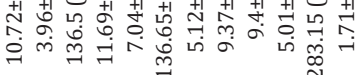

$$
\neg \text { 少 }
$$

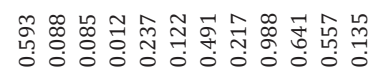

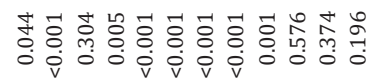

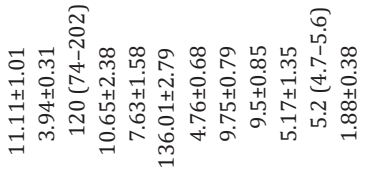

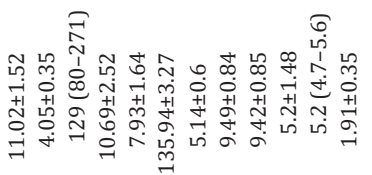

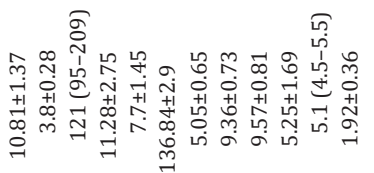

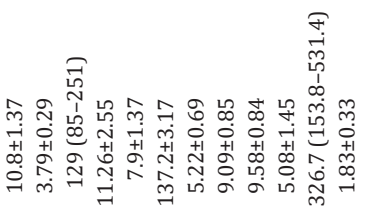

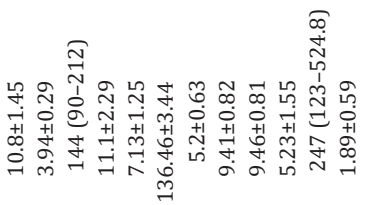

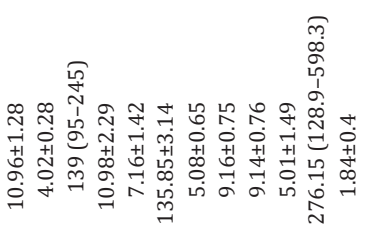

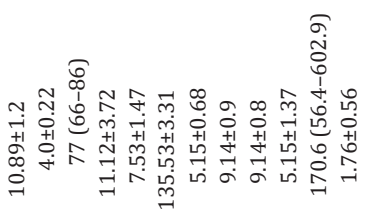

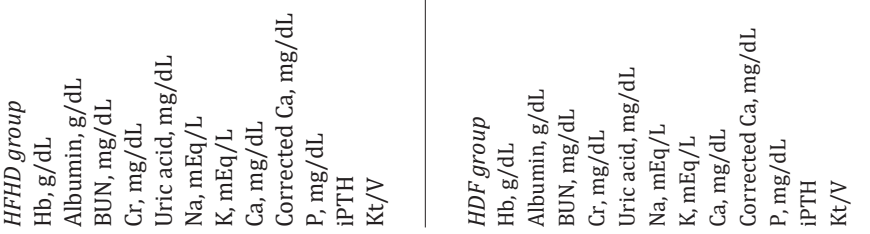

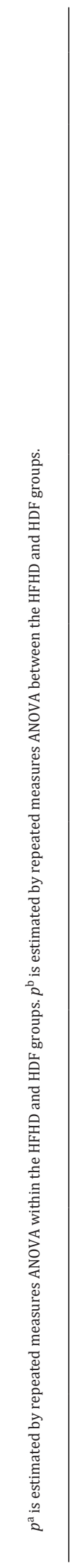


Table 3. Associations of longitudinal changes in laboratory measurements in the HFHD and HDF groups from 2009 to 2014 on the basis of a mixed effects model

\begin{tabular}{|c|c|c|c|c|c|c|}
\hline \multirow[t]{2}{*}{ Dependent variables } & \multicolumn{3}{|l|}{ Model 1} & \multicolumn{3}{|l|}{ Model 2} \\
\hline & Coefficient (95\% CI) & SE & $p$ & Coefficient $(95 \% \mathrm{CI})$ & SE & $p$ \\
\hline $\mathrm{Hb}(\mathrm{g} / \mathrm{dL})$ & $0.41(0.12$ to 0.69$)$ & 0.14 & 0.005 & $-0.04(-0.11$ to 0.03$)$ & 0.04 & 0.259 \\
\hline Albumin $(\mathrm{g} / \mathrm{dL})$ & $0.03(-0.04$ to 0.09$)$ & 0.03 & 0.431 & $-0.02(-0.03$ to 0.0002$)$ & 0.01 & 0.053 \\
\hline BUN (mg/dL) & $3.24(-5.61$ to 12.08$)$ & 4.51 & 0.473 & $0.72(-0.99$ to 2.43$)$ & 0.87 & 0.411 \\
\hline $\mathrm{Cr}(\mathrm{mg} / \mathrm{dL})$ & 40.31 (5.89 to 74.72$)$ & 17.56 & 0.022 & $-2.49(-8.69$ to 3.7$)$ & 3.16 & 0.431 \\
\hline Uric acid (mg/dL) & $-3.54(-7.12$ to 0.03$)$ & 1.82 & 0.052 & $0.9(-0.05$ to 1.85$)$ & 0.48 & 0.062 \\
\hline $\mathrm{Na}(\mathrm{mEq} / \mathrm{L})$ & $-0.35(-0.85$ to 0.15$)$ & 0.26 & 0.174 & $0.04(-0.05$ to 0.12$)$ & 0.04 & 0.406 \\
\hline $\mathrm{K}(\mathrm{mEq} / \mathrm{L})$ & $0.08(-0.22$ to 0.39$)$ & 0.16 & 0.598 & $-0.003(-0.08$ to 0.07$)$ & 0.04 & 0.933 \\
\hline $\mathrm{Ca}(\mathrm{mg} / \mathrm{dL})$ & $-0.92(-1.54$ to -0.29$)$ & 0.32 & 0.004 & $-0.02(-0.19$ to 0.14$)$ & 0.08 & 0.785 \\
\hline Corrected Ca (mg/dL) & $-0.01(-0.17$ to -0.18$)$ & 0.09 & 0.959 & $0.07(0.02$ to 0.11$)$ & 0.02 & 0.005 \\
\hline $\mathrm{P}(\mathrm{mg} / \mathrm{dL})$ & $0.06(-0.07$ to 0.19$)$ & 0.07 & 0.384 & $0.001(-0.04$ to 0.04$)$ & 0.02 & 0.965 \\
\hline iPTH (pg/mL) & $-126.32(-230.38$ to -22.26$)$ & 53.09 & 0.017 & $16.94(-11.04$ to 44.92$)$ & 14.28 & 44.923 \\
\hline $\mathrm{Kt} / \mathrm{V}$ & $0.03(-0.14$ to 0.2$)$ & 0.09 & 0.766 & $0.05(0.01$ to 0.1$)$ & 0.02 & 0.025 \\
\hline
\end{tabular}

Group (HDF vs. HFHD) as an independent variable. Both models control for fixed factors including age, hemodialysis vintage, gender, and comorbidity. Model 1 includes fixed factors only. Model 2 includes fixed factors and added terms for each measurement and its interaction with time.

Table 4. Calcified scores in aortic arch between the HDF and HFHD groups

\begin{tabular}{lccc}
\hline Calcified scores & HFHD $(n=108)$ & HDF $(n=102)$ & $p$ \\
\hline Initial & & & $0.030^{*}$ \\
0 & $25(69.44 \%)$ & $52(50.98 \%)$ & \\
1 & $11(10.52 \%)$ & $26(25.49 \%)$ & \\
2 & $2(1.85 \%)$ & $8(14.71 \%)$ & 0.004 \\
3 & $0(0-3)$ & $0(0-3)$ & $0.854^{*}$ \\
Initial (median, range) & $0.44 \pm 0.75$ & $0.79 \pm 0.97$ & \\
Initial (mean \pm SD) & $22(20.37 \%)$ & $23(22.55 \%)$ & 0.892 \\
Secondary & $16(14.81 \%)$ & $15(14.71 \%)$ & $22(21.57 \%)$ \\
0 & $29(26.85 \%)$ & $41(40.2 \%)$ & $2(0-3)$ \\
1 & $41(37.96 \%)$ & $1.8 \pm 1.2$ & \\
2 & $2(0-3)$ & $<0.001$ & \\
3 & $1.82 \pm 1.15$ & & \\
Secondary (median, range) & $<0.001$ & 0.008 & \\
Secondary (mean \pm SD) & & & \\
\hline Paired $p$ & & & \\
\hline Repeated ANOVA $p$ & & & \\
\hline
\end{tabular}

$p$ is estimated using independent two-sample $t$ test to determine the difference between the HFHD and HDF groups for mean \pm SD. * $p$ is estimated using Fisher's exact or chi-squared test for category $0-3$. Paired $p$ is estimated using paired $t$ test to determine the difference in two time point measurements for each group. Repeated ANOVA $p$ is estimated by repeated measures ANOVA to determine the difference of longitudinal changes between the HFHD and HDF groups. 
Table 5. Linear regression analysis for hospitalization frequency

\begin{tabular}{|c|c|c|c|c|}
\hline \multirow[t]{2}{*}{ Characteristics } & \multicolumn{2}{|l|}{ Univariate } & \multicolumn{2}{|l|}{ Full-adjusted } \\
\hline & Coefficient (95\% CI) & $p$ & Coefficient (95\% CI) & $p$ \\
\hline Group (HDF vs. HFHD) & $-0.44(-1.2$ to 0.33$)$ & 0.259 & $-0.04(-0.84$ to 0.76$)$ & 0.926 \\
\hline Age & $0.02(-0.02$ to 0.06$)$ & 0.239 & $0.01(-0.04$ to 0.05$)$ & 0.775 \\
\hline Dialysis vintage (years) & $-0.03(-0.09$ to 0.03$)$ & 0.315 & $0.03(-0.03$ to 0.1$)$ & 0.316 \\
\hline Gender (male vs. female) & $0.24(-0.53$ to 1.01$)$ & 0.537 & $0.39(-0.64$ to 1.42$)$ & 0.458 \\
\hline \multicolumn{5}{|l|}{ Comorbidity } \\
\hline DM & 1.54 (0.69 to 2.39$)$ & $<0.001$ & $0.32(-0.81$ to 1.45$)$ & 0.575 \\
\hline Hepatitis B & $-0.95(-2.37$ to 0.46$)$ & 0.186 & $0.12(-1.52$ to 1.75$)$ & 0.888 \\
\hline Hepatitis C & $1.68(0.68$ to 2.68$)$ & 0.001 & $0.66(-0.45$ to 1.77$)$ & 0.244 \\
\hline $\mathrm{Hb}(\mathrm{g} / \mathrm{dL})$ & $-0.29(-0.58$ to 0.01$)$ & 0.059 & $-0.04(-0.36$ to 0.29$)$ & 0.830 \\
\hline Albumin (g/dL) & $-2.54(-3.99$ to -1.09$)$ & 0.001 & $-1.43(-3.09$ to 0.23$)$ & 0.092 \\
\hline BUN (mg/dL) & $0.02(-0.0005$ to 0.05$)$ & 0.055 & $0.04(0.003$ to 0.07$)$ & 0.032 \\
\hline $\mathrm{Cr}(\mathrm{mg} / \mathrm{dL})$ & $-0.16(-0.34$ to 0.02$)$ & 0.077 & $-0.3(-0.56$ to -0.03$)$ & 0.027 \\
\hline Uric acid (mg/dL) & $0.04(-0.25$ to 0.34$)$ & 0.770 & $-0.12(-0.44$ to 0.2$)$ & 0.445 \\
\hline $\mathrm{Na}(\mathrm{mEq} / \mathrm{L})$ & $-0.03(-0.14$ to 0.09$)$ & 0.634 & $0.02(-0.1$ to 0.14$)$ & 0.742 \\
\hline $\mathrm{K}(\mathrm{mEq} / \mathrm{L})$ & $-0.05(-0.67$ to 0.56$)$ & 0.861 & $-0.22(-0.84$ to 0.41$)$ & 0.498 \\
\hline $\mathrm{Ca}(\mathrm{mg} / \mathrm{dL})$ & $-0.64(-1.12$ to -0.16$)$ & 0.009 & $-0.25(-0.82$ to 0.33$)$ & 0.396 \\
\hline $\mathrm{P}(\mathrm{mg} / \mathrm{dL})$ & $0.1(-0.17$ to 0.37$)$ & 0.456 & $0.22(-0.13$ to 0.56$)$ & 0.215 \\
\hline iPTH (pg/mL) & $-0.0004(-0.001$ to 0.0003$)$ & 0.272 & $-0.0005(-0.001$ to 0.0003$)$ & 0.235 \\
\hline $\mathrm{Kt} / \mathrm{V}$ & $-1.37(-2.48$ to -0.25$)$ & 0.017 & $-2.1(-3.56$ to -0.63$)$ & 0.005 \\
\hline
\end{tabular}

Coefficient (95\% CI) and $p$ are estimated using univariate or full-adjusted multivariate linear regression analysis.

in HDF group, $p=0.004$, respectively) and became non-significant in the secondary phase (2014). Statistical methods were also used to compare the numbers of AAC grading in each category between the two groups. A high number of participants in the grade 0 AAC at the initial phase $(p=0.030)$ progressed to the severe form of calcified grading in the secondary phase $(p=0.854)$. This indicated that the progression of AAC was parallel in both groups over the 6-year follow-up. The two-time points in each group showed significant changes $(p<$ 0.001 in HFHD group, $p<0.001$ in HDF group, respectively). The comparison of longitudinal changes between the HFHD and HDF groups also exhibited statistical significance $(p=0.008)$.

By linear regression analysis with full adjustment, no significant difference was observed in hospitalization frequency (beta $-0.04,95 \% \mathrm{CI}-0.84$ to $0.76, p=0.926$ ) and days of hospitalization (beta $0.55,95 \% \mathrm{CI}-16.26$ to $17.36, p=0.948$ ) between the HDF and HFHD groups (Tables 5, 6).

There were not significantly different in hospitalization frequency and length between AAC progressors and non-progressors (see online supplementary Table S1, available at www. karger.com/doi/10.1159/000499645).

\section{Discussion}

One of objectives in the present study was to examine the trends of longitudinal changes in the serum small soluble solute concentrations among patients receiving HFHD and online HDF. We followed up these participants over 6 years. In short, majority of blood concentrations of selected variables in both groups demonstrated significant changes over follow-up years compared with the baseline concentrations. ANOVA analysis revealed significant changes in serum $\mathrm{Cr}$ concentrations between the two groups, higher values at the baseline 
Hao et al.: Hospitalization Rate and Aortic Arch Calcification between HDF and HFHD

Table 6. Linear regression analysis for total length (days) in hospitalization

\begin{tabular}{|c|c|c|c|c|}
\hline \multirow[t]{2}{*}{ Characteristics } & \multicolumn{2}{|l|}{ Univariate } & \multicolumn{2}{|l|}{ Full-adjusted } \\
\hline & Coefficient (95\% CI) & $p$ & Coefficient $(95 \%$ CI $)$ & $p$ \\
\hline Group (HDF vs. HFHD) & $0.14(-14.35$ to 14.63$)$ & 0.985 & $0.55(-16.26$ to 17.36$)$ & 0.948 \\
\hline Age & $0.77(0.06$ to 1.49$)$ & 0.035 & $0.22(-0.66$ to 1.09$)$ & 0.623 \\
\hline Dialysis vintage (years) & $-1.3(-2.37$ to -0.23$)$ & 0.017 & $-0.55(-1.99$ to 0.9$)$ & 0.455 \\
\hline Gender (male vs. female) & $1.5(-12.99$ to 15.98$)$ & 0.839 & $4.07(-17.63$ to 25.76$)$ & 0.711 \\
\hline \multicolumn{5}{|l|}{ Comorbidity } \\
\hline DM & $38.76(23.11$ to 54.41$)$ & $<0.001$ & $23.22(-0.64$ to 47.07$)$ & 0.056 \\
\hline Hepatitis B & $-9.48(-36.34$ to 17.37$)$ & 0.487 & $13.41(-21.02$ to 47.83$)$ & 0.442 \\
\hline Hepatitis C & $36.3(17.54$ to 55.06$)$ & $<0.001$ & $21.16(-2.25$ to 44.56$)$ & 0.076 \\
\hline $\mathrm{Hb}(\mathrm{g} / \mathrm{dL})$ & $-1.22(-7.58$ to 5.14$)$ & 0.705 & $3.84(-2.997$ to 10.68$)$ & 0.268 \\
\hline Albumin $(\mathrm{g} / \mathrm{dL})$ & $-30.72(-62.33$ to 0.89$)$ & 0.057 & $-8.42(-43.39$ to 26.56$)$ & 0.634 \\
\hline BUN (mg/dL) & $0.14(-0.395$ to 0.67$)$ & 0.611 & $0.52(-0.165$ to 1.2$)$ & 0.136 \\
\hline $\mathrm{Cr}(\mathrm{mg} / \mathrm{dL})$ & $-5.43(-9.13$ to -1.72$)$ & 0.004 & $-7.52(-13.1$ to -1.94$)$ & 0.009 \\
\hline Uric acid (mg/dL) & $1.83(-4.4$ to 8.06$)$ & 0.562 & $1.39(-5.33$ to 8.11$)$ & 0.682 \\
\hline $\mathrm{Na}(\mathrm{mEq} / \mathrm{L})$ & $-1.52(-3.98$ to 0.93$)$ & 0.222 & $-0.71(-3.18$ to 1.76$)$ & 0.568 \\
\hline $\mathrm{K}(\mathrm{mEq} / \mathrm{L})$ & $7(-5.93$ to 19.93$)$ & 0.286 & $4.26(-8.99$ to 17.51$)$ & 0.525 \\
\hline $\mathrm{Ca}(\mathrm{mg} / \mathrm{dL})$ & $-9.6(-19.92$ to 0.73$)$ & 0.068 & $-0.38(-12.42$ to 11.67$)$ & 0.950 \\
\hline$P(\mathrm{mg} / \mathrm{dL})$ & $1.04(-4.62$ to 6.7$)$ & 0.717 & $3.88(-3.4$ to 11.15$)$ & 0.293 \\
\hline iPTH $(\mathrm{pg} / \mathrm{mL})$ & $-0.01(-0.03$ to 0.003$)$ & 0.119 & $-0.01(-0.03$ to 0.01$)$ & 0.205 \\
\hline $\mathrm{Kt} / \mathrm{V}$ & $-16.75(-40.64$ to 7.15$)$ & 0.168 & $-21.56(-52.41$ to 9.3$)$ & 0.169 \\
\hline
\end{tabular}

Coefficient $(95 \% \mathrm{CI})$ and $p$ are estimated using univariate or full-adjusted multivariate linear regression analysis.

and follow-up years in participants receiving HFHD than HDF. When full adjustment was further applied and the time effect was considered, there was not significantly different in serum concentration of soluble small solutes between HDF group and HFHD group. Thus, our results demonstrated that both HFHD and online HDF renal replacement therapy contributed equally to the clearance of small soluble solutes in patients with ESRD. Based on this observation, online HDF therapy has no superior benefit for small solute clearance comparing with HFHD.

A review of the literature revealed that only few long-term follow-up observational studies comparing online HDF with HFHD at a wide-range of molecular weight solutes' removal have been conducted. One small study observed 31 patients receiving online HDF therapy for a 4-year follow-up period. Results showed that the participants had more beta2-microglobulin removal and increased Kt/V values after HDF therapy. The blood concentrations in small solutes and $\mathrm{Hb}$ did not demonstrate significant changes [28]. Another randomized study with a 12-month follow-up showed that online HDF had superior removal of small (BUN, Cr) and large (beta-2-microglobulin, complement factor D) solutes than HFHD [29]. However, the improved removal in these solutes did not result in lower pre-dialysis blood concentrations. The possible mechanisms were mass transfer rates of solutes in the body and rebound phenomenon after dialysis. Results in the present study revealed constant blood concentrations in small soluble solutes over the 6-year period in online HDF and HFHD, that is compatible with previous studies [28, 29].

AAC is very common in ESRD [10], especially in patients on HD [30]. This circumstance is consequent to stiffness in vascular wall and reduce vascular compliance, which have been found to be predictive of cardiovascular mortality [27]. The pathogenesis of AAC in patients on dialysis is multiple and complex. The relevant factors include dysregulation of $\mathrm{Ca}$ and phosphate, hyperparathyroidism, underlying comorbid diseases, dialysis vintage, and age 
Kidney
Blood Pressure

Research

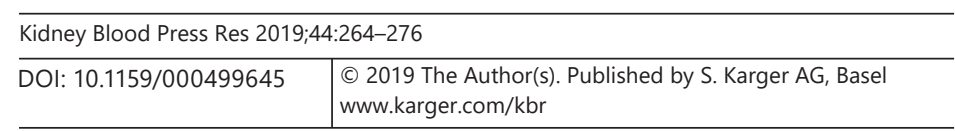

Hao et al.: Hospitalization Rate and Aortic Arch Calcification between HDF and HFHD

[31]. HDF has been reported in one cross-sectional study exhibiting no given benefits in terms of vascular stiffness compared to HD [32]. Moreover, HDF has also been demonstrated to have no benefits compared to HFHD with respect to mineral metabolism and blood pressure control in one retrospective study with a large sample size [33]. In the present study, we tried to examine the benefit of HDF on vascular complication through indirect evidence by plain chest radiography. We found that patients on HDF and HFHD all forward to higher levels of AAC over the 6-year period. Nevertheless, we advise caution in interpreting this result. We did not measure all potential indicators for mineral metabolism in our study. Although routine indicators such as $\mathrm{Ca}, \mathrm{P}$, and iPTH were not significantly different between the two groups over the 6-year period by time-varying adjustment, other potential uremic toxins for VC, such as, indoxyl sulfate and p-cresol, were not examined in our study. Furthermore, our study is limited by its retrospective review design and the potential selection bias in choice for dialysis modality. To resolve the possibility of HDF benefit on vascular complication, we expect more clinical studies involving a large sample size and more information concerning uremic toxins removal by HDF in the future.

In comparison with the general population, various symptoms and complications led to high hospitalization rates in patients with kidney disease [34]. In the early National Cooperative Dialysis Study, hospitalization was greater in the high-BUN group [35]. Owing to this observation, clinical studies were conducted to prove the reduced rates of hospitalization by higher permeability membrane for dialysis therapy. The rate of hospital admission was not significantly different between HFHD and conventional HD in one early study [36]. This early observation was also documented later in the Hemodialysis (HEMO) study [37]. HDF combines convective and diffusive solute removal in one dialysis therapy. It is well known that HDF provides better removal of both small and large solutes than HFHD [29]. Accordingly, we hypothesized that HDF conferred to reduce rate of hospital admission than HFHD. Our study showed rates of hospitalization were 735 per 1,000 patients in HDF versus 852 per 1,000 patients in HFHD. These rates are lower than the nationwide report from the Taiwan Society of Nephrology, 968 per 1,000 patients [38]. We also found that hospitalization frequency and days of hospitalizations were not significantly different between HDF and HFHD over the 6 -year period. The main cause of hospital admission was cardiovascular diseases in both groups. Although the rate of hospitalization was lower in HDF than in HFHD, we interpreted this result with caution because potential selection bias may exist owing to the retrospective design. Furthermore, various confounding factors were unidentified in the medical record review. The cause-effect relationship cannot be concluded in our study. As per our knowledge, clinical studies investigating hospitalization rate between HDF and HFHD are lacking. Our study is unique as it involves a 6-year follow-up period. The results indicate that compared with HFHD, HDF has potential benefits in reducing hospitalization rate. Therefore, further studies are warranted to validate our results.

The present study has several limitations. First, the present study was a retrospective medical record review, the observational period lasted for 6 years and various confounding factors were not identified completely. This bias may affect our results. Second, patients in the HDF group already received regular HD prior to this cross-sectional study. Therefore, the effect of previous HD on clinical outcomes in our study could not have been considered in the final analysis. Third, convective volume used in post-dilution HDF patients was diverse. This may result in bias against the substantial contribution of high convective volume used in HDF. Finally, the sample size was relatively small in our study. The strengths of the present study are the availability of data on several patient characteristics, which were collected using a standardized method over a long-term period, and the clinical practice of dialysis therapy in one HD unit was more generalized. Furthermore, the malpractice associated with each 
nephrologist was avoided. Finally, to the best of our knowledge, this study is the first to utilize plain chest radiography to investigate AAC between HDF and HFHD.

In conclusion, online post-dilution HDF is a safe therapy and is at least as effective as HFHD in maintaining small solute removal and dialysis adequacy. We also provided unique comparative data of AAC and hospitalization rates between HDF and HFHD.

This study suggests that HDF is not superior to HFHD.

\section{Acknowledgment}

The authors would like to thank the nurses in the HD center for their dedication to data collection.

\section{Statement of Ethics}

This study was approved by the Institutional Review Board and Ethics Committee of Chang Gung Memorial Hospital (documentation No. 101-1595B) and conducted according to the Declaration of Helsinki. In keeping with the retrospective data review regulations of the Committee on Human Research of Kaohsiung Chang Gung Memorial Hospital, signed informed consent from the study participants was not required.

\section{Disclosure Statement}

The authors declare no conflicts of interest.

\section{Funding Sources}

Research funding was provided by Chang Gung Memorial Hospital Research Program (CMRPG8D1151).

Tianjin Science and Technology Program (No. 15ZXLCSY00020).

Research Project of Tianjin Municipal Commission of Health and Family Planning on key areas of Traditional Chinese Medicine (2018004).

The Science \&Technology Development Fund of Tianjin Education Commission for Higher Education (2017KJ157).

Research Project of Tianjin Municipal Commission of Health and Family Planning on TCM and Combination of Chinese Traditional and Western Medicine (2017116).

\section{Author Contributions}

N.H. and J.-B.C. drafted the manuscript. J.-B.C. and T.T.-Y.C. conceived and designed the idea of this research. Y.-P.W. and W.-T.L. collected the data. Y.-Y.L. executed data check-up. C.-H.Y. critically reviewed data and management. H.-T.Y. and C.-H.W. performed English editing. All authors read and approved the final manuscript. 


\begin{tabular}{l|l}
\hline Kidney Blood Press Res 2019;44:264-276 \\
\hline DOI: 10.1159/000499645 & $\begin{array}{l}\text { (c) 2019 The Author(s). Published by S. Karger AG, Basel } \\
\text { www.karger.com/kbr }\end{array}$ \\
\hline
\end{tabular}

Hao et al.: Hospitalization Rate and Aortic Arch Calcification between HDF and HFHD

\section{References}

1 Bansal N, McCulloch CE, Rahman M, Kusek JW, Anderson AH, Xie D, et al.; CRIC Study Investigators. Blood pressure and risk of all-cause mortality in advanced chronic kidney disease and hemodialysis: the chronic renal insufficiency cohort study. Hypertension. 2015 Jan;65(1):93-100.

2 Tesař V, Wanner C, Quaschning T, Rychlík I. Chronic renal failure and its complications. Kidney Blood Press Res. 2011;34(4):202.

3 Di Lullo L, House A, Gorini A, Santoboni A, Russo D, Ronco C. Chronic kidney disease and cardiovascular complications. Heart Fail Rev. 2015;20:259-272.

4 Jurgensen JS, Grimm R, Benz K, Philipp S, Eckardt KU, Amann K. Effects of anemia and uremia and a combination of both on cardiovascular structures. Kidney Blood Press Res. 2010;33:274-81.

5 Ronco C. Hemodiafiltration: technical and clinical issues. Blood Purif. 2015;40 Suppl 1:2-11.

6 Penne EL, van der Weerd NC, van den Dorpel MA, Grooteman MP, Lévesque R, Nubé MJ, et al.; CONTRAST Investigators. Short-term effects of online hemodiafiltration on phosphate control: a result from the randomized controlled Convective Transport Study (CONTRAST). Am J Kidney Dis. 2010 Jan;55(1):77-87.

7 Morena M, Jaussent A, Chalabi L, Leray-Moragues H, Chenine L, Debure A, et al.; FRENCHIE Study Investigators. Treatment tolerance and patient-reported outcomes favor online hemodiafiltration compared to highflux hemodialysis in the elderly. Kidney Int. 2017 Jun;91(6):1495-509.

8 Panichi V, Rizza GM, Paoletti S, Bigazzi R, Aloisi M, Barsotti G, et al.; RISCAVID Study Group. Chronic inflammation and mortality in haemodialysis: effect of different renal replacement therapies. Results from the RISCAVID study. Nephrol Dial Transplant. 2008 Jul;23(7):2337-43.

9 Carracedo J, Merino A, Nogueras S, Carretero D, Berdud I, Ramírez R, et al. On-line hemodiafiltration reduces the proinflammatory CD14+CD16+ monocyte-derived dendritic cells: A prospective, crossover study. J Am Soc Nephrol. 2006 Aug;17(8):2315-21.

10 Yap YS, Ting KT, Chi WC, Lin CH, Liu YC, Chuang WL. Aortic arch calcification predicts patency loss of arteriovenous fistula in end-stage renal disease patients. Sci Rep. 2016 Apr;6(1):24943.

11 Locatelli F, Altieri P, Andrulli S, Bolasco P, Sau G, Pedrini LA, et al. Hemofiltration and hemodiafiltration reduce intradialytic hypotension in ESRD. J Am Soc Nephrol. 2010 Oct;21(10):1798-807.

12 Canaud B, Bragg-Gresham JL, Marshall MR, Desmeules S, Gillespie BW, Depner T, et al. Mortality risk for patients receiving hemodiafiltration versus hemodialysis: european results from the DOPPS. Kidney Int. 2006 Jun;69(11):2087-93.

13 Grooteman MP, van den Dorpel MA, Bots ML, Penne EL, van der Weerd NC, Mazairac AH, et al.; CONTRAST Investigators. Effect of online hemodiafiltration on all-cause mortality and cardiovascular outcomes. J Am Soc Nephrol. 2012 Jun;23(6):1087-96.

14 Ok E, Asci G, Toz H, Ok ES, Kircelli F, Yilmaz M, et al.; Turkish Online Haemodiafiltration Study. Mortality and cardiovascular events in online haemodiafiltration (OL-HDF) compared with high-flux dialysis: results from the Turkish OL-HDF Study. Nephrol Dial Transplant. 2013;28:192-202.

15 Maduell F, Moreso F, Pons M, Ramos R, Mora-Macià J, Carreras J, et al.; ESHOL Study Group. High-efficiency postdilution online hemodiafiltration reduces all-cause mortality in hemodialysis patients. J Am Soc Nephrol. 2013 Feb;24(3):487-97.

16 Abd ElHafeez S, Tripepi G, Mallamaci F, Zoccali C. Aldosterone, mortality, cardiovascular events and reverse epidemiology in end stage renal disease. Eur J Clin Invest. 2015 0ct;45(10):1077-86.

17 Rastogi A. Sevelamer revisited: pleiotropic effects on endothelial and cardiovascular risk factors in chronic kidney disease and end-stage renal disease. Ther Adv Cardiovasc Dis. 2013 Dec;7(6):322-42.

18 Staude H, Jeske S, Schmitz K, Warncke G, Fischer DC. Cardiovascular risk and mineral bone disorder in patients with chronic kidney disease. Kidney Blood Press Res. 2013;37(1):68-83.

19 Ferris ME, Miles JA, Seamon ML. Adolescents and young adults with chronic or end-stage kidney disease. Blood Purif. 2016;41(1-3):205-10.

20 Komatsu M, Okazaki M, Tsuchiya K, Kawaguchi H, Nitta K. Aortic arch calcification predicts cardiovascular and all-cause mortality in maintenance hemodialysis patients. Kidney Blood Press Res. 2014;39(6):658-67.

21 Mahnken AH, Wein BB, Sinha AM, Günther RW, Wildberger JE. Value of conventional chest radiography for the detection of coronary calcifications: comparison with MSCT. Eur J Radiol. 2009 Mar;69(3):510-6.

22 Izumi M, Morita S, Nishian Y, Miyamoto T, Kasumoto H, Oue M, et al. Switching from calcium carbonate to sevelamer hydrochloride has suppressive effects on the progression of aortic calcification in hemodialysis patients: assessment using plain chest X-ray films. Ren Fail. 2008;30(10):952-8.

23 Bannas P, Jung C, Blanke P, Treszl A, Derlin T, Adam G, et al. Severe aortic arch calcification depicted on chest radiography strongly suggests coronary artery calcification. Eur Radiol. 2013 0ct;23(10):2652-7.

24 Adar A, Erkan H, Gokdeniz T, Karadeniz A, Cavusoglu IG, Onalan O. Aortic arch calcification is strongly associated with coronary artery calcification. Vasa. 2015 Mar;44(2):106-14.

25 Inoue T, Ogawa T, Ishida H, Ando Y, Nitta K. Aortic arch calcification evaluated on chest X-ray is a strong independent predictor of cardiovascular events in chronic hemodialysis patients. Heart Vessels. 2012 Mar;27(2): 135-42.

26 Daugirdas JT. The post: pre-dialysis plasma urea nitrogen ratio to estimate K.t/V and NPCR: mathematical modeling. Int J Artif Organs. 1989 Jul;12(7):411-9.

27 Lee CT, Huang CC, Hsu CY, Chiou TT, Ng HY, Wu CH, et al. Calcification of the aortic arch predicts cardiovascular 
and all-cause mortality in chronic hemodialysis patients. Cardiorenal Med. 2014 Apr;4(1):34-42. Muñoz R, Gallardo I, Valladares E, Saracho R, Martínez I, Ocharan J,
clinical experience. Hemodial Int. 2006 Jan;10(s1 Suppl 1):S28-32.

29 Ward RA, Schmidt B, Hullin J, Hillebrand GF, Samtleben W. A comparison of on-line hemodiafiltration and high-flux hemodialysis: a prospective clinical study. J Am Soc Nephrol. 2000 Dec;11(12):2344-50.

30 Ogawa T, Ishida H, Akamatsu M, Matsuda N, Fujiu A, Ito K, et al. Progression of aortic arch calcification and all-cause and cardiovascular mortality in chronic hemodialysis patients. Int Urol Nephrol. 2010 Mar;42(1): 187-94.

31 Sage AP, Tintut Y, Demer LL. Regulatory mechanisms in vascular calcification. Nat Rev Cardiol. 2010 Sep; 7(9): 528-36.

32 Charitaki E, Davenport A. Does hemodiafiltration reduce vascular stiffness measured by aortic pulse wave velocity compared with high-flux hemodialysis? Hemodial Int. 2014 Apr;18(2):391-5.

33 Vilar E, Fry AC, Wellsted D, Tattersall JE, Greenwood RN, Farrington K. Long-term outcomes in online hemodiafiltration and high-flux hemodialysis: a comparative analysis. Clin J Am Soc Nephrol. 2009 Dec;4(12):194453.

34 Daratha KB, Short RA, Corbett CF, Ring ME, Alicic R, Choka R, et al. Risks of subsequent hospitalization and death in patients with kidney disease. Clin J Am Soc Nephrol. 2012 Mar;7(3):409-16.

35 Lowrie EG, Laird NM, Parker TF, Sargent JA. Effect of the hemodialysis prescription of patient morbidity: report from the National Cooperative Dialysis Study. N Engl J Med. 1981 Nov;305(20):1176-81.

36 Hornberger JC, Chernew M, Petersen J, Garber AM. A multivariate analysis of mortality and hospital admissions with high-flux dialysis. J Am Soc Nephrol. 1992 Dec;3(6):1227-37.

37 Locatelli F, Martin-Malo A, Hannedouche T, Loureiro A, Papadimitriou M, Wizemann V, et al.; Membrane Permeability Outcome (MPO) Study Group. Effect of membrane permeability on survival of hemodialysis patients. J Am Soc Nephrol. 2009 Mar;20(3):645-54.

38 Cannata-Andia JB, Roman-Garcia P, Hruska K. The connections between vascular calcification and bone health. Nephrol Dial Transplant. 2011 Nov;26(11):3429-36. 